\title{
Photodynamic Therapy in Vulvar Dystrophy Treatment
}

\section{Dunaevskaya $\mathrm{V}^{1^{*}}$, Tzerkovsky $\mathbf{D A}^{2}$}

${ }^{1}$ Head of laboratory of Photodynamic therapy and hyperthermia with chemotherapy group, Ukraine

${ }^{2}$ N.N. Alexandrov National Cancer Center, 223040, Lesnoy, Republic of Belarus

*Corresponding Author: Dunaevskaya V, Head of laboratory of Photodynamic therapy and hyperthermia with chemotherapy group, Ukraine, E-mail: leilabellila1@gmail.com

Received: 09 February 2018; Accepted: 23 February 2018; Published: 01 March 2018

\begin{abstract}
In this article, the authors analyzed and systematized the main aspects of the treatment of vulvar dystrophic diseases (VDD). The traditional methods of treatment of this pathology are surgical intervention and non-surgical methods (high-intensity laser radiation, laser $\mathrm{CO}_{2}$ coagulation, vaporization with radiation intensity of more than 1000 $\mathrm{W} / \mathrm{cm}^{2}$ of treatment, chemotherapy and immune-modulatory therapy). Despite the effectiveness of these methods, their main deficiency is the high incidence of local recurrence of the disease (from 17\% to 48\%). The authors present the PDT method as an alternative, organ-preserving and highly effective therapeutic option. Most studies are devoted to the use of 5-ALA and chlorin-based photosensitizers in the treatment of VDD. The authors studied in detail the world experience of PDT for VDD, analyzed and systematized the results of treatment, advantages and disadvantages of the method.
\end{abstract}

Keywords: Vulvar dystrophic diseases; Surgical and non-surgical methods; Photodynamic therapy; Photosensitizer

\section{Introduction}

In recent years there has been an increase in the number of vulvar dystrophic diseases (VDDs), making from $0.6 \%$ up to $6 \%$ of all cases in the gynecological incidence $[1,2]$. This pathology, united by the term neurodystrophic diseases, includes sclerotic lichen (kraurosis), vulvar squamous cell hyperplasia (leukoplakia, vulvar intraepithelial neoplasia (VIN)) and other dermatoses [3].

Vulvar leukoplakia is the main manifestation of squamous cell hyperplasia, which is a VDD characterized by lesion of stratified squamous noncornified (nonkeratinized) epithelium. Epidemiological structure of benign lesions of the vulva is subdivided into squamous cell hyperplasia (53.3\%), sclerotic lichens $(25.3 \%)$, and their aggregation $(27.4 \%$ 
of all cases). According to Judson P.L. et al., the incidence rate of VIN between 1973 and 2000 increased by 411\% from 0.56 to 2.86 cases per 100000 women [4].

The urgency of the problem is largely associated with the high risk of carcinomatous degeneration developed in connection with this gynecological pathology: in $9 \%$ of cases of kraurosis, $5 \%-20 \%$ of VINs, $5 \%-31.2 \%$ of cases when these two processes are combined [5]. Welsher L.Z. et al. report that vulvar malignant pathology occurs in $20 \%-60 \%$ of patients suffering from dystrophic diseases of this localization [6].

\section{Key Methods of Treatment}

The problem of vulvar precancerous diseases treatment remains urgent also due to the insufficient efficacy of existing treatment methods, disease duration, severity of its course and the likelihood of malignancy [7].

Surgical removal is the major treatment method for the patients having VDDs (lesions excision and vulvectomy in cases of morbidity). The main advantage of this method is the possibility of removing all clinically detected lesions with histological verification and risk of malignancy calculation $[8,9,10]$. Surgical treatment, despite its higher efficacy in comparison with other methods, is characterized by trauma, high relative frequency of postoperative complications, unsatisfactory cosmetic and functional results. The frequency (rate) of local relapses also remains relatively high (up to $30 \%-46 \%$ ) $[11,12]$.

At the same time, in order to preserve the integrity of the vulvar ring and to achieve good cosmetic results, nonsurgical methods of treatment remain priority for the patients in their thirties and younger. The main non-surgical methods of treatment are high-intensity laser radiation, laser $\mathrm{CO}_{2}$ coagulation and vaporization of vulva areas with radiation intensity of more than $1000 \mathrm{~W} / \mathrm{cm}^{2}[11,13,14,16,17]$. The main disadvantages of laser coagulation and vaporization are high traumatism and recurrence rate (from $17.5 \%$ up to $48.3 \%$ at long-term follow-up) and the inability to eradicate human papillomavirus. While laser coagulation removes the affected vulvar tissue, etiopathogenetic mechanisms of the disease remain unaffected, which causes development of local relapses in the early periods after treatment.

Imiquimod, being an immunomodifier, has certain therapeutic potential $[18,19]$ with the frequency of local relapses exceeding $40 \%$ [20, 21]. Use of 5-fluorouracil application forms in the treatment of VINs is characterized by low rate of total (complete) regressions (TRs) (34\%) and the development of adverse reactions (grade I-II burns, painful sores) [22].

A prospective area of research is the use of high-intensity focused ultrasound. Thus, Jia Y. et al. report safety of its use, high rate of histologically confirmed TRs (88.9\%), absence of clinical symptoms of the disease and malignancy within 6-month term [23]. 
The main reasons for the search of new methods in VDDs treatment are frequent recurrence of the process, long and persistent course of the disease, unreasonable and inefficient use of medicines, which leads to the development of various psychosomatic disorders in patients that adversely affect the body state as a whole and cause degradation of the women's quality of life $[2,17]$. The existing conservative methods of treatment while reducing the main symptom - itching of the external genitalia - do not provide complete elimination of local morphological manifestations of the disease, nor give long-term remissions, at the same time require long course of treatment. In addition, lengthy conservative therapy does not prevent malignancy of the disease.

\subsection{Photodynamic Therapy With 5-Aminolevulinic Acid}

Photodynamic therapy (PDT) is one of the most promising areas in the treatment of VDDs. The use of PDT in gynecology began with treatment of vesical cervix malignant neoplasms [24, 25, 26, 27].

Photodynamic therapy is also indicated as an alternative organ-preserving method in the treatment of precancerous vulvar diseases. This method of treatment is based on the use of a special substance - a photosensitizer (PS), cytotoxicity of which multiplies when exposed to specific wavelength laser irradiation. The result of photoirradiation (PI) of the pre-sensitized tissue is apoptosis, autophagy and ischemic necrosis of the irradiated tissue area $[28,29]$.

Photodynamic therapy with the use of 5-aminolevulinic acid (5-ALA) and chlorine derivatives with their local administration have been described as VDDs treatment methods [30, 31, 32, 33, 34]. However, with external use of PS, the efficacy of treatment is low compared to traditional methods (no effect is observed in $25 \%-30 \%$ of cases) [35].

Most of the published clinical studies conducted abroad, confirming the efficacy of PDT, include the use of 5-ALA application form as PS. Major results of the studies are presented in Table 1.

\begin{tabular}{|l|l|l|l|l|}
\hline Authors & $\begin{array}{l}\text { Patients, } \\
\text { clinical diagnosis }\end{array}$ & $\begin{array}{l}\text { PS, } \\
\text { dose }\end{array}$ & $\begin{array}{l}\text { Parameters of } \\
\text { photo-irradiation } \\
(\lambda, \text { ED) }\end{array}$ & Treatment results \\
\hline $\begin{array}{l}\text { Hillemanns P. } \\
\text { et al., 2000 [31] }\end{array}$ & $\begin{array}{l}\text { N=25 } \\
\text { VIN I/III degree }\end{array}$ & $\begin{array}{l}20 \% \\
5-A L A \\
\text { solution }\end{array}$ & $\begin{array}{l}\lambda=635 \mathrm{~nm} \\
100 \mathrm{~J} / \mathrm{cm}^{2}\end{array}$ & $\begin{array}{l}\text { With VIN I degree, mono- and bi- } \\
\text { focal VIN II/III degree TR rate is } \\
100 \% \text {; with the multifocal form of } \\
\text { VIN II-III degree TR rate is } 27 \%\end{array}$ \\
\hline $\begin{array}{l}\text { Fehr M.K. } \\
\text { et al., 2001 [36] }\end{array}$ & VIN III degree & $\begin{array}{l}\text { Nel } \% 5-A L A \\
\text { gel }\end{array}$ & $\begin{array}{l}\lambda=635 \mathrm{~nm} \\
120 \mathrm{~J} / \mathrm{cm}^{2}\end{array}$ & $\begin{array}{l}\text { After 2 months: } \\
\text { Histological TR rate is } 73.3 \% . \\
\text { Recurrence rate is } 20 \%\end{array}$ \\
\hline Fehr M.K. & $\mathrm{N}=22$ & $10 \% 5$-ALA & $\lambda=635 \mathrm{~nm}$ & Clinical TR rate is $66 \%$. \\
\hline
\end{tabular}




\begin{tabular}{|c|c|c|c|c|}
\hline et al., 2002 [37] & VIN II/III degree & gel & $80-125 \mathrm{~J} / \mathrm{cm}^{2}$ & Histological TR rate is $57 \%$. \\
\hline $\begin{array}{l}\text { Biniszkiewicz T. } \\
\text { et al., } 2004 \text { [38] }\end{array}$ & $\begin{array}{l}\mathrm{N}=24 \\
\text { lichen } \\
\text { sclerosis }\end{array}$ & $\begin{array}{l}16 \% \\
5 \text {-ALA } \\
\text { cream }\end{array}$ & $\begin{array}{l}3-6 \text { sessions } \\
\lambda=635 \mathrm{~nm} \\
180 \mathrm{~J} \\
700 \mathrm{~mW} / \mathrm{cm}^{2}\end{array}$ & $\begin{array}{l}\text { No manifestation of the disease } \\
\text { symptoms with } 17 \text { patients. }\end{array}$ \\
\hline $\begin{array}{l}\text { Raspagliesi F. } \\
\text { et al., 2006 [39] }\end{array}$ & $\begin{array}{l}\mathrm{T}=7 \\
\text { Recurrent form of } \\
\text { Paget's disease }\end{array}$ & $\begin{array}{l}16 \% \\
5 \text {-ALA } \\
\text { cream }\end{array}$ & $\begin{array}{l}\lambda=620 \mathrm{~nm} \\
37 \mathrm{~J} / \mathrm{cm}^{2}\end{array}$ & $\begin{array}{l}\text { Clinical TR rate is } 57 \% \text {. } \\
\text { All patients had pain syndrome } \\
\text { and soft tissue edema. }\end{array}$ \\
\hline $\begin{array}{l}\text { Winters U. } \\
\text { et al., } 2008[40]\end{array}$ & $\begin{array}{l}\mathrm{N}=20 \\
\text { VIN II/III degree }\end{array}$ & $\begin{array}{l}20 \% \\
5 \text {-ALA } \\
\text { solution }+ \\
\text { imiquimod }\end{array}$ & $\begin{array}{l}\lambda=635 \mathrm{~nm} \\
100 \mathrm{~J} / \mathrm{cm}^{2}\end{array}$ & $\begin{array}{l}\text { Clinical TR rate after PDT is } 55 \% \text {, } \\
\text { after PDT }+ \text { imiquimod }-64 \% \text {. } \\
\text { The median of asymptomatic } \\
\text { period of } 52 \text { weeks observed with } \\
65 \% \text { of patients. }\end{array}$ \\
\hline $\begin{array}{l}\text { Zawislak A. } \\
\text { et al., } 2009 \text { [41] }\end{array}$ & $\begin{array}{l}\mathrm{N}=23 \\
\mathrm{VIN} \text { II/III degree }\end{array}$ & $\begin{array}{l}20 \% \\
5 \text {-ALA } \\
\text { solution }\end{array}$ & $\begin{array}{l}\lambda=635 \mathrm{~nm} \\
100 \mathrm{~J} / \mathrm{cm}^{2}\end{array}$ & $\begin{array}{l}\text { Clinical TR rate is } 52 \% \text {. } \\
\text { Histological TR rate is } 38 \% \text {. }\end{array}$ \\
\hline
\end{tabular}

Table 1: Clinical studies confirming the efficacy of PDT, include the use of 5-ALA application form as PS.

\subsection{Photodynamic Therapy With Chlorine-Based Photosensitizers}

In the CIS countries, in addition to derivatives of 5-ALA, radachlorine, photoditazine and a number of other chlorine e6 derivatives are often applied. Otdelnova O.B. et al. presented the results of treatment of 6 patients with benign vulvar diseases ( 4 with sclerotic vulvar lichen and 2 with squamous vulvar hyperplasia). PDT was performed using photoditazine PS in combination of intravenous administration at a dose of $1 \mathrm{mg} / \mathrm{Kg}$ and application on the affected area of $1 \mathrm{ml}$ of $0.5 \%$ penetration gel of the preparation. PI was carried out with a semiconducting Atcus-2 laser under local anesthesia with a $2 \%$ lidocaine solution in ED $100-200 \mathrm{~J} / \mathrm{cm}^{2}$ for $10-30$ minutes. The efficacy was estimated on the basis of unbiased examination and presence of clinical symptoms of the disease (itching). After 3 months of observation, the therapeutic effect remained. Three out of four patients with sclerotic lichen noticed absence of itching, and cytological examination of scrapings and vulvoscopy indicated complete cure of all patients with squamous cell hyperplasia. Good cosmetic result was recorded in all the cases. At the same time, all patients had a side effect of treatment in the form of moderately and strongly expressed pain syndrome during PI which limited the use of an adequate therapeutic dose of irradiation to the lesions [35].

The same authors demonstrated the efficacy of PDT in a patient with sclerotic vulvar lichen in combination with a papillomavirus infection. The patient underwent a radio wave removal of the vulvar papilloma and a photo irradiation of the affected area. Photoditazine in the form of intravenous solution was used as PS at the dose of 1 $\mathrm{mg} / \mathrm{kg}$ of body weight. PI of the vulva was administered 2 hours after the infusion of the preparation with the help of 
Atcus-2 diode laser device $(\lambda=662 \mathrm{~nm})$ in the fractional regime in ED 100-250 J/ $\mathrm{cm}^{2}$. The authors report that in the course of the treatment, a good clinical effect and elimination of the human papilloma virus have been achieved [33].

Ivanova L.V. et al. presented the results of treatment of 4 patients with vulvar dysplasia I-II degree using PDT method with radachlorine ( $0.35 \%$ solution) in the form of intravenous drip infusion and $1 \%$ introvaginal gel. Two hours after the administration of the preparation, the mucosal PI was performed using Atcus-2 laser (2W, 300-600 $\mathrm{mW} / \mathrm{cm}^{2}, 360 \mathrm{~J} / \mathrm{cm}^{2}$ ). The number of irradiation fields varied depending on the prevalence of the pathological process. The procedure was carried out once. Two out of four patients with neoplasia of the vulva did not have any effect from the therapy, partial epithelialization was observed with 1 patient and complete epithelialization was noticed with 1 patient. Based on the preliminary data obtained, the authors concluded that local use of PS is rather ineffective [42].

Makarov O.V. et al. examined and treated 97 patients with VDDs: 75 of them were diagnosed with sclerotic vulvar lichen (77.3\%), 18 patients had squamous vulvar hyperplasia (18.6\%), and 4 women showed mixed dystrophy (4.1\%). PDT was performed with photoditazine PS (VETA GRAND, Russia). The $1^{\text {st }}$ group consisted of 64 patients who received PS by intravenous drip at a dose of $1 \mathrm{mg} / \mathrm{kg}$; group 2 included 33 patients who received PS locally by application of $0.5 \%$ penetration gel. PI was performed in a continuous or fractional mode $(\lambda=662 \mathrm{~nm}, 100-250$ $\left.\mathrm{J} / \mathrm{cm}^{2}, 2 \mathrm{~mW}\right)$. TR was noted in $58(90.6 \%)$ of 64 patients of the $1^{\text {st }}$ group within one year after the session and in 26 (78.8\%) of 33 patients of the $2^{\text {nd }}$ group. The number of relapses one year after the PDT session in the first group was $9.1 \%$, in the second group it made up $22.6 \%$. Additional session of PDT was required for 5 patients of the $2^{\text {nd }}$ group having sclerotic lichen (20.8\%) and 2 patients with squamous cell hyperplasia (28.6\%), after which a clinical cure was diagnosed [43].

Ivanova L.V. et al. evaluated the efficacy of treatment of 18 patients having VDDs with the help of PDT and radachlorine - one of the most widely used last generation PS (RADA PHARMA, Russia) in the form of gel $-0.5 \%$ RadaGel with exposure time of 60 minutes. PI was carried out with a laser $\left(2 \mathrm{~W}, \lambda=662 \mathrm{~nm}, 250-300 \mathrm{~J} / \mathrm{cm}^{2}\right)$. All patients noted quality of life improvement, which was manifested by absence of itching in 16 of them (88.9\%). During clinical examination the recovery of volume and natural coloration of large and small labia, improvement of elasticity, flexibility and trophism of tissues was noted [44].

Khashukoieva A.Z. et al. performed PDT with the use of photoditazine as PS at a dose of $1 \mathrm{mg} / \mathrm{kg}, 50$ patients with VDDs were tested: sclerotic lichen was verified in 32 of them, 10 had squamous cell hyperplasia, and 8 had mixed dystrophy. PI was carried out in a continuous fractional mode in ED 100-250 J/ $\mathrm{cm}^{2}(\lambda=662 \mathrm{~nm})$. Clinical regression was noted in 47 patients (94\%). All sessions were accompanied by a slightly marked pain syndrome [45]. The same team of authors presents data on 82 patients with benign vulvar diseases treated with PDT: photoditazine was administered to 64 of them as intravenous drip at a dose of $1 \mathrm{mg} / \mathrm{kg}$ (group 1), 18 patients had an application of $0.5 \%$ penetration gel (group 2). PI was performed in continuous or fractional modes in ED $100-250 \mathrm{~J} / \mathrm{cm}^{2}$. A 
positive therapeutic effect was achieved after 2 months in 100\% of cases. Within 1 year the relapse rates for the first and the second groups were $10.7 \%$ and $21.4 \%$ respectively. The authors concluded that PDT with systemic administration of PS is an effective option in treatment of this pathology and has fewer side effects and complications [46].

Filonenko E.V. et al. described the case of the successful use of PDT for treatment of a patient with vulvar dysplasia (III degree) with intravenous administration of photolon PS at a dose of $1 \mathrm{mg} / \mathrm{Kg}$ of body weight. The PDT session was performed 3 hours after the administration of PS, ED $-350 \mathrm{~J} / \mathrm{cm}^{2}$. As a result of PDT, a TR of tumor was obtained. Within 8 months of follow-up observation, local recurrence of the disease was not detected [47].

\subsection{Photodynamic Therapy With Other Types Of Photosensnitizers}

Chulkova E.A. et al. examined and treated 90 patients with dystrophic and premalignant vulvar diseases using PDT method in combination with $20 \%$ Alasens ointment. The changes characteristic of the VIN I-III and cancer were observed with 27 of the patients in situ. The radiation power averaged $1.5 \mathrm{~W}$ in the spectral range $\lambda=630 \pm 10 \mathrm{~nm}$. The authors noted that PDT with the application of $20 \%$ of Alasens ointment proved to be an effective and simple method, minimally and selectively injuring the vulva tissue, which is of great importance for young and middle-aged patients [48].

Rusakevich P.S. et al. in their publication presented detailed results of PDT with methylene blue in 115 patients with neurodystrophic vulvar diseases. The PDT method encompassed: laser device (joint domestic invention of the Institute of Physics, the National Academy of Sciences of Belarus, AXICON Unitary Enterprise, the NAS of Belarus and LUZAR Production Company) with $\lambda=670 \pm 2 \mathrm{~nm}$, power density of $150-300 \mathrm{~mW} / \mathrm{cm}^{2}$, with the total manipulation time of 10 minutes for the entire target pathological area, in 5 sessions. A 1\% solution of methylene blue, prepared on a 5\% aqueous solution of sodium bicarbonate, was applied as PS. The authors believe that the proposed method is characterized by high clinical efficacy due to the speed-up and normalization of metaplasia, probably due to pronounced (88.8\%) anti-inflammatory effect. These parameters for the control group were $70.5 \%$, respectively [34].

\section{Discussion}

VDD is a serious medical and social problem in patients of young and middle age. In recent years there has been an increase in the number of VDD, making from 0.6 up to $6 \%$ of all cases in the gynecological incidence $[1,2]$. The urgency of the problem is largely associated with the high risk of carcinomatous degeneration developed in connection with this gynecological pathology: in $9 \%$ of cases of kraurosis, $5 \%-20 \%$ of VINs, $5 \%-31.2 \%$ of cases when these two processes are combined [5]. The traditional methods of treatment of this pathology are surgical intervention and non-surgical methods (high-intensity laser radiation, laser $\mathrm{CO}_{2}$ coagulation, vaporization with radiation intensity of more than $1000 \mathrm{~W} / \mathrm{cm}^{2}$ of treatment, chemotherapy and immune-modulatory therapy). Despite the effectiveness of these methods, their main deficiency is the high incidence of local recurrence of the disease (from $17 \%$ to $48 \%$ ) [8-22]. 
In connection with this fact, there is a need to search for new methods of treatment of this serious pathology. One such approach is PDT is a method as an alternative, organ-preserving for traditional. The results of the research demonstrated in this article testify to the high frequency of clinical and histological regressions, low frequency of local relapses.

In our opinion, the main indications for the use of PDT in the treatment of VDD are:

1. Histologically verified diagnosis

2. Primary, recurrent and residual pathological foci

3. Pathological foci of anatomically inconvenient localization

4. Pathological foci resistant to traditional methods of treatment

5. Patient's refusal from surgery, chemotherapy and others

6. Multiple and extensive pathological foci lesions.

\section{Conclusion}

The results of the clinical use of the PDT method in combination with photolon PS in treatment of patients with background and precancerous vulvar diseases testify to its high therapeutic efficacy, few complications or side reactions and good cosmetic results. PDT is convenient in use, so it can be recommended for outpatient care for VDDs treatment and vulvar cancer prevention.

In conclusion, we can summarize that PDT has a number of advantages in comparison with traditional methods of treatment of VDD, such as:

1. Minimal toxicity for the surrounding normal tissues, due to the selective accumulation of the photosensitizer in the tumor

2. Absence of mechanisms of primary and acquired resistance

3. Possibility of an outpatient procedure

4. Possibility of combination with other methods of treatment

5. Possibility of repeated repetition of the procedure

6. Ease of use in the multiple nature of the lesion

7. Good cosmetic results

8. Possibility of implementing organ-preserving methods of treatment.

\section{References}

1. Jones RW, Rowan DM, Stewart AW. Vulvar intraepithelial neoplasia: aspects of the natural history and outcome in 405 women. Obstet Gynecol 106 (2005): 1319-1326.

2. Reyes MC, Cooper K. An update on vulvar intraepithelial neoplasia: terminology and a practical approach to diagnosis. J Clin Pathol 67 (2014): 290-294.

3. Hendriks J, Wilkinson EJ. Vulvar lichen sclerosus: immunohistologic. J Reprod Med 38 (1994): 37-40. 
4. Judson PL, Habermann EB, Baxter NN, et al. Trends in the incidence of invasive and in situ vulvar carcinoma. Obstet Gynecol 107 (2006): 1018-1022.

5. Kozachenko VP. Oncogynecology: a guide for doctors. Moscow: Medicine 2006: 560.

6. Velsher LZ, Stakhanov ML, Krylova EN. Treatment of patients with premalignant diseases of skin, mucous membrane of the external genitalia and perineum with the help of low-intensity and high-energy laser radiation. Las Med 12 (2008): 21-25.

7. Rogovskaya SI, Bebneva TN. Leukoplakia of cervix, vagina and vulva: Modern aspects. Diseases of the vagina and cervix 1 (2014): 51-55.

8. Gu Y, Zhu L, Li X, et al. Surgical treatment of usual type vulvar intraepithelial neoplasia: a study at three academic hospitals. Chin Med J (Engl) 127 (2014): 784-786.

9. Mahner S, Wölber L. Surgery or topical therapy for vulval intraepithelial neoplasia. Lancet Oncol 15 (2014): 1287-1288.

10. Lavoué V, Lemarrec A, Bertheuil N, et al. Quality of life and female sexual function after skinning vulvectomy with split-thickness skin graft in women with vulvar intraepithelial neoplasia or vulvar Paget disease. Eur J Surg Oncol 39 (2013): 1444-1450.

11. Hillemanns $\mathrm{P}$, Wang $\mathrm{X}$, Staehle $\mathrm{S}$, et al. Evaluation of different treatment modalities for vulvar intraepithelial neoplasia (VIN): $\mathrm{CO}_{2}$ laser vaporization, photodynamic therapy, excision and vulvectomy. Gynecol Oncol 100 (2005): 271-275.

12. Modesitt SC, Waters AB, Walton L, et al. Vulvar intraepithelial neoplasia III: occult cancer and the impact of margin status on recurrence. Obstet Gynecol 92 (1998): 962-966.

13. Sideri M, Spinaci L, Spolti N, et al. Evaluation of $\mathrm{CO}_{2}$ laser excision or vaporization for the treatment of vulvar intraepithelial neoplasia. Gynecol Oncol 75 (1999): 277-281.

14. Penna $\mathrm{C}$, Fallani $\mathrm{MG}$, Fambrini $\mathrm{M}$, et al. $\mathrm{CO}_{2}$ laser surgery for vulvar intraepithelial neoplasia. Excisional, destructive and combined techniques. J Reprod Med 47 (2002): 913-918.

15. Hillemanns $\mathrm{P}$, Wang $\mathrm{X}$, Staehle S. et al. Evaluation of different treatment modalities for vulvar intraepithelial neoplasia (VIN): $\mathrm{CO}_{2}$ laser vaporization, photodynamic therapy, excision and vulvectomy. Gynecol Oncol 100 (2005): 271-275.

16. Kushnir CL, Fleury AC, Hill MC, et al. The use of argon beam coagulation in treating vulvar intraepithelial neoplasia III: a retrospective review. Gynecol Oncol 131 (2013): 386-388.

17. Wallbillich JJ, Rhodes HE, Milbourne AM, et al. Vulvar intraepithelial neoplasia (VIN 2/3): comparing clinical outcomes and evaluating risk factors for recurrence. Gynecol Oncol 127 (2012): 312-315.

18. Iavazzo C, Pitsouni E, Athanasiou S, et al. Imiquimod for treatment of vulvar and vaginal intraepithelial neoplasia. Int J Gynaecol Obstet 101 (2008): 3-10.

19. Kim JM, Lee HJ, Kim SH, et al. Efficacy of $5 \%$ imiquimod cream on vulvar intraepithelial neoplasia in Korea: pilot study. Ann Dermatol 27 (2015): 66-70.

20. Gentile M, Bianchi P, Sesti F, et al. Adjuvant topical treatment with imiquimod 5\% after excisional surgery for VIN 2/3. Eur Rev Med Pharmacol Sci 18 (2014): 2949-2952. 
21. Westermann C, Fischer A, Clad A. Treatment of vulvar intraepithelial neoplasia with topical 5\% imiquimod cream. Int J Gynaecol Obstet 120 (2013): 266-270.

22. Preti M, Van Seters M, Sideri M, et al. Squamous vulvar intraepithelial neoplasia. Clin Obstet Gynecol 48 (2005): 845-861.

23. Jia $\mathrm{Y}, \mathrm{Wu} \mathrm{J}, \mathrm{Xu} \mathrm{M}$, et al. Clinical responses to focused ultrasound applied to women with vulval intraepithelial neoplasia. J Ultrasound Med 33 (2014): 1903-1908.

24. Istomin YP, Lapzevich TP, Chalau VN, et al. Photodynamic therapy of cervical intraepithelial neoplasia grades II and III with Photolon. Photodiagnosis Photodyn Ther 7 (2010): 144-151.

25. Shishkova N, Kuznetsova O, Berezov T. Photodynamic therapy for gynecological diseases and breast cancer. Cancer Biol Med 9 (2012): 9-17.

26. Choi MC, Jung SG, Park H, et al. Photodynamic therapy for management of cervical intraepithelial neoplasia II and III in young patients and obstetric outcomes. Lasers Surg Med 45 (2013): 564-572.

27. Tao XH, Guan Y, Shao D, et al. Efficacy and safety of photodynamic therapy for cervical intraepithelial neoplasia: a systemic review. Photodiagnosis Photodyn Ther 11 (2014): 104-112.

28. Dougherty TJ, Gomer CJ, Henderson BW, et al. Photodynamic therapy. J Nat Cancer Ins 90 (1998): 889905.

29. Mroz P, Yaroslavsky A, Kharkwal GB, et al. Cell death pathways in photodynamic therapy of tumors. Cancers 3 (2011): 2516-2539.

30. Martin-Hirsch PL, Whitehurst C, Buckley C. Photodynamic treatment for lower genital tract intraepithelial neoplasia. Lancet 351(1998): 1403-1405.

31. Hillemanns P, Untch M, Dannecker C, et al. Photodynamic therapy of vulvar intraepithelial neoplasia using 5-aminolevulinic acid. Int J Cancer 85 (2000): 649-653.

32. Ignatova TP, Rusakevich PS, Rogov YI. Clinical and morphological aspects of vulvar dystrophic diseases during photodynamic therapy with methylene blue. Oncol J 2 (2008): 105-125.

33. Khashukoieva AZ, Otdelnova OB, Kupeeva YS. Photodynamic therapy in treatment of vulvar dystrophic diseases combined with papillomavirus infection. Treatment and prevention 2 (2012): 78-80.

34. Rusakevich PS, Grishanovich RV, Plavskiy VY. Possibilities of using photodynamic therapy with local application of photosensitizers in neurodystrophic diseases of the vulva, cervical ectopia and metaplasia. Oncol J 4 (2010): 47-53.

35. Otdelnova OB, Khashukoieva AZ, Ibragimova MI. Possibilities of photodynamic therapy using photoditazine photosensitizer in gynecological diseases treatment. Ros bioter J 7 (2008): 47-52.

36. Fehr MK, Hornung R, Schwarz VA, et al. Photodynamic therapy of vulvar intraepithelial neoplasia III using topically applied 5-aminolevulinic acid. Gynecol Oncol 80 (2001): 62-66.

37. Fehr MK, Hornung R, Degen A, et al. Photodynamic therapy of vulvar and vaginal condyloma and intraepithelial neoplasia using topically applied 5-aminolevulinic acid. Lasers Surg Med 30 (2002): 273-279.

38. Biniszkiewicz T, Olejekb A, Kozak-Darmasb I, et al. Therapeutic effects of 5-ALA-induced photodynamic therapy in vulvar lichen sclerosus. Photodiagnosis Photodyn Ther 2 (2005): 157-160. 
39. Raspagliesi F, Fontanelli R, Rossi G, et al. Photodynamic therapy using a methyl ester of 5aminolevulinic acid in recurrent Paget's disease of the vulva: a pilot study. Gynecol Oncol 103 (2006): 58186.

40. Winters U, Daayana S, Lear JT, et al.Clinical and immunologic results of a phase II trial of sequential imiquimod and photodynamic therapy for vulval intraepithelial neoplasia. Clin Cancer Res 14 (2008): 52925299.

41. Zawislak A, Donnelly RF, McCluggage WG, et al. Clinical and immunohistochemical assessment of vulval intraepithelial neoplasia following photodynamic therapy using a novel bioadhesive patch-type system loaded with 5-aminolevulinic acid. Photodiagnosis Photodyn Ther 6 (2009): 28-40.

42. Ivanova LV, Savinov IP, Fedina EV. The role of photodynamic therapy in the treatment of HPVassociated lesions of the cervix, vagina and vulva. J Obstetr Women's Dis LVIII (2009): 62-63.

43. Makarov OV, Khashukoieva AZ, Kupeeva ES, et al. Treatment of vulvar dystrophic diseases using photodynamic therapy. Bull. Rus. State Med. Univ 4 (2014): 49-52.

44. Topical issues of medicine in modern conditions / Collection of scientific papers on the results of the international scientific-practical conference. 2015; 2: St. Petersburg, 2015: 205.

45. Khashukoieva AZ, Kupeeva ES, Otdelnova OB. Photodynamic therapy in vulvar dystrophic diseases treatment. Photodyn Ther Photodiagn 1 (2012): 31.

46. Khashukoieva AZ, Kupeeva ES, Narimanova MR. Photodynamic therapy for vulvar dystrophic disease. Photodyn Ther Photodiagn 3 (2013): 53-54.

47. Filonenko EV, Serova LG. Clinical observation of successful photodynamic therapy of a patient with severe vulvar dysplasia. Photodyn Ther Photodiagn 4 (2014): 42.

48. Chulkova EA, Makarov IO, Sokolov VV. Modern aspects of fluorescent diagnostics and photodynamic therapy with 5-aminolevulinic acid with background and precancerous diseases of the vulva. J Obstetr Women's Dis LVIII (2009): m91-m92.

Citation: Dunaevskaya V, Tzerkovsky DA. Photodynamic Therapy in Vulvar Dystrophy Treatment. Archives of Clinical and Biomedical Research 2 (2018): 042-051. 